$06.4 ; 09.5$

\title{
Влияние механической вибрации на оптические свойства инфракрасных световодов состава $\mathrm{AgCl}-\mathrm{AgBr}$
}

\author{
(C) А.С. Шмыгалев, А. Тураби, Д.А. Васильева, Б.П. Жилкин, Л.В. Жукова \\ Уральский федеральный университет им. Б.Н. Ельцина, Екатеринбург, Россия \\ E-mail: a.s.shmygalev@urfu.ru
}

Поступило в Редакцию 27 августа 2019г.

В окончательной редакции 27 августа 2019г.

Принято к публикации 7 февраля 2020 г.

\begin{abstract}
Исследовано влияние механической вибрации на оптическое пропускание инфракрасных световодов составов $\mathrm{AgCl}_{0.25} \mathrm{Br}_{0.75}$ и $\mathrm{AgCl}_{0.5} \mathrm{Br}_{0.5}$ в течение $30 \mathrm{~h}$. Показано, что вибрационное воздействие на световоды приводит к снижению их пропускания. Обнаружен селективный характер пропускания инфракрасных световодов в диапазонах длин волн $2.0-4.0$ и $6.0-9.0 \mu \mathrm{m}$.
\end{abstract}

Ключевые слова: инфракрасные световоды, твердые растворы галогенидов серебра, оптическое пропускание, механические вибрации.

DOI: 10.21883/PJTF.2020.09.49365.18020

Волоконно-оптические кабели являются наиболее современными, быстрыми и помехозащищенными каналами передачи информационного сигнала. В последние годы ввиду достаточной изученности и наличия материальной базы передача информации в диапазоне длин волн $0.2-2.0 \mu \mathrm{m}$ по кварцевым и полимерным волокнам получила широкое распространение. Вместе с тем передача данных в среднем и дальнем инфракрасных (ИК) диапазонах по-прежнему остается актуальной задачей. Среди инфракрасных материалов, наиболее перспективными являются монокристаллы на основе твердых растворов галогенидов серебра [1]. Эти кристаллы обладают набором ценных свойств [2], из которых технологически важным является возможность изготовления из них методом экструзии инфракрасных световодов.

Инфракрасные световоды на основе твердых растворов галогенидов серебра прозрачны в широком диапазоне от 2.0 до $25.0 \mu \mathrm{m}$ при показателе преломления 2.2-2.4 [3]. Кроме того, такие волокна нетоксичны, негигроскопичны и обладают низкими оптическими потерями $(0.1 \mathrm{~dB} / \mathrm{m})$ [2]. Сегодня ИК-световоды нашли применение в ИК-спектроскопии [4] и медицине [5], а также используются для дистанционного измерения температуры различных нагретых тел [6]. В частности, ИК-волокна могут применяться для проведения тепловизионной диагностики труднодоступных объектов, таких как внутренние узлы и детали газотурбинных установок (ГТУ). При этом на передачу теплового излучения по инфракрасным световодам будут влиять различные факторы, в том числе вибрационный режим работы ГТУ. Поэтому важным аспектом практического применения ИК-волокон является изучение влияния вибрации на их оптические свойства. Проведенный анализ литературных данных показал, что, во-первых, результаты таких исследований отсутствуют, а во-вторых, что определяю- щими являются вибрационные характеристики кожуха турбины, который при установившемся режиме работы ГТУ резонирует с частотой $50 \mathrm{~Hz}$ и амплитудой $1 \mathrm{~mm}[7]$.

Для исследования влияния вибрации на передачу теплового излучения были выбраны два инфракрасных световода. Первое волокно состава $\mathrm{AgCl}_{0.25} \mathrm{Br}_{0.75}$ имело длину $1.1 \mathrm{~m}$ и диаметр $1.12 \mathrm{~mm}$, а второе волокно состава $\mathrm{AgCl}_{0.5} \mathrm{Br}_{0.5}$ - длину 0.16 т и диаметр $0.525 \mathrm{~mm}$. Световоды были помещены в защитную оболочку из полиэфирэфиркетона (PEEK), а их торцы были вмонтированы в коннекторы SMA-905. Испытания проводились на вибрационном стенде, позволявшем создавать вибрационную нагрузку в диапазонах частот от 20 до $1000 \mathrm{~Hz}$ и амплитуд от 0.1 до $10 \mathrm{~mm}$. Процедура испытаний заключалась в следующем.

Предварительно с помощью инфракрасного фурьеспектрометра японской фирмы Shimadzu измерялись спектры пропускания световодов. Затем образцы помещались в специальный держатель, который закреплялся на рабочей поверхности вибрационного стенда. В дальнейшем волокна подвергались вибрационному воздействию общей продолжительностью $30 \mathrm{~h}$. Съемка спектров пропускания осуществлялась после воздействия вибрацией в течение 10, 13 и $30 \mathrm{~h}$. Полученные экспериментальные данные формировались как изменение пропускания путем вычитания спектров, измеренных после вибрационного воздействия, из первоначальных. На рис. 1 и 2 представлено изменение в зависимости от длины волны оптического пропускания ИК-световодов составов $\mathrm{AgCl}_{0.25} \mathrm{Br}_{0.75}$ и $\mathrm{AgCl}_{0.5} \mathrm{Br}_{0.5}$ соответственно.

Результаты измерений показали, что пропускная способность ИК-световода состава $\mathrm{AgCl}_{0.25} \mathrm{Br}_{0.75}$ заметно ухудшается после $10 \mathrm{~h}$ приложения вибрации и достигает средних потерь $30 \%$ во всем диапазоне длин волн 


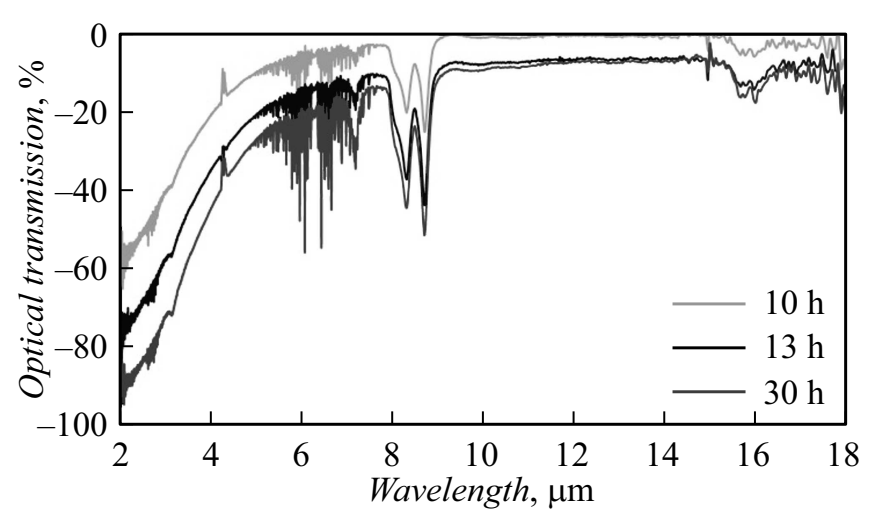

Рис. 1. Изменение пропускания инфракрасного световода состава $\mathrm{AgCl}_{0.25} \mathrm{Br}_{0.75}$ от длины волны при различной длительности вибрационного воздействия.

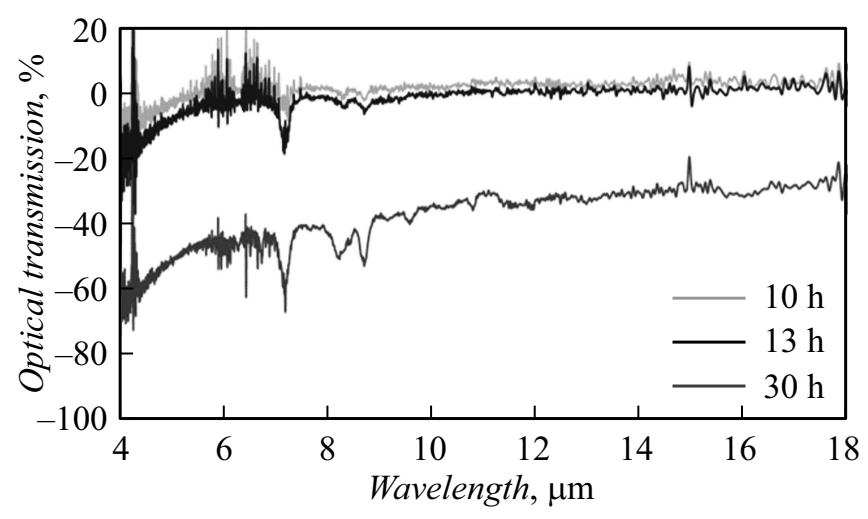

Рис. 2. Изменение пропускания инфракрасного световода состава $\mathrm{AgCl}_{0.5} \mathrm{Br}_{0.5}$ от длины волны при различной длительности вибрационного воздействия.

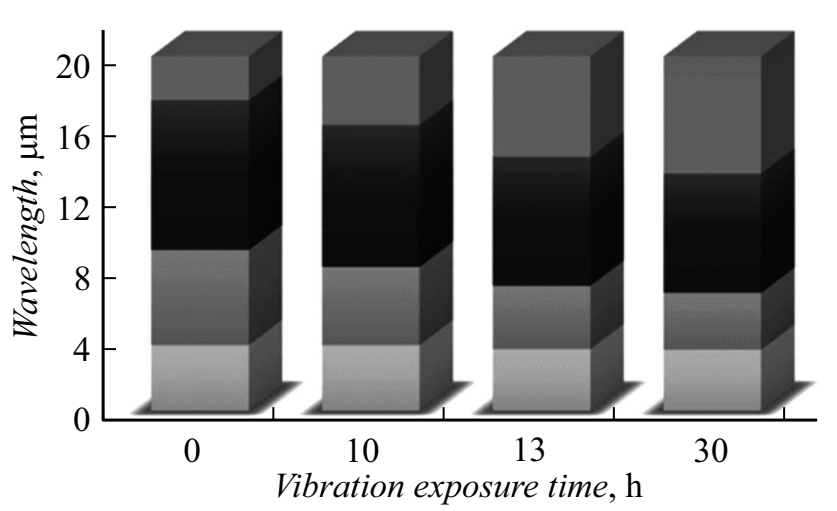

Рис. 3. Гистограмма распределения оптического пропускания в зависимости от длины волны и времени вибрационного воздействия.

к 30-му часу испытаний. Пропускание световода состава $\mathrm{AgCl}_{0.5} \mathrm{Br}_{0.5}$ практически не изменялось в течение $13 \mathrm{~h}$. На этой стадии следует отметить появление небольшого эффекта просветления в диапазоне длин волн
4.5-7.0 $\mu \mathrm{m}$. Однако после $30 \mathrm{~h}$ было выявлено повышение доли потерь оптического излучения, составившее $50 \%$. При этом в случае состава $\mathrm{AgCl}_{0.25} \mathrm{Br}_{0.75}$ наблюдается селективное изменение оптического пропускания. Так, в ближнем инфракрасном диапазоне от 2.0 до $4.0 \mu \mathrm{m}$, а также в среднем от 6.0 до $9.0 \mu \mathrm{m}$ присутствуют области резкого снижения оптического пропускания. В то же время в диапазоне длин волн 9.0-15.0 $\mu \mathrm{m}$ такого эффекта не наблюдается. На рис. 3 представлена гистограмма распределения оптического пропускания в зависимости от длины волны при различном времени вибрационного воздействия.

Таким образом, на основании полученных данных можно сделать вывод, что характерное для энергомашин вибрационное воздействие с частотой $50 \mathrm{~Hz}$ и амплитудой $1 \mathrm{~mm}$ оказывает негативное влияние на пропускающую способность ИК-световодов. Выявлен селективный характер влияния механической вибрации на инфракрасные световоды. Для исключения негативных последствий воздействия вибрации при использовании световодов следует жестко закреплять волокно, а также применять комплекс мер антивибрационной защиты. На основании полученных экспериментальных данных будет разрабатываться алгоритм экстраполяции изменений пропускной способности световодов на более длительные сроки вибрационного воздействия. Вместе с тем представленные данные могут служить основой для создания технологии контролируемого вибрационного воздействия с целью создания оптических фильтров.

\section{Благодарности}

Авторы благодарят А.С. Корсакова за предоставление инфракрасных световодов.

\section{Конфликт интересов}

Авторы заявляют, что у них нет конфликта интересов.

\section{Список литературы}

[1] Полякова Г.В., Лисицкий И.С. Галогениды таллия и серебра - уникальные оптические материалы для приборов инфракрасной, лазерной и радиационной техники // Актуальные вопросы современных математических и естественных наук. Екатеринбург: ИЦРОН, 2016. С. 24-27.

[2] Жукова Л.В., Корсаков А.С., Львов А.Е., Салимгареев Д.Д. Волоконные световоды для среднего инфракрасного диапазона. Екатеринбург: Изд-во УМЦ УПИ, 2016. 247 с.

[3] Korsakov A.S., Vrublevsky D.S., Zhukova L.V. // Opt. Mater. 2015. V. 50. Part B. P. 204-207.

DOI: $10.1016 /$ j.optmat.2015.10.025

[4] Eccleston R., Wolf C., Balsam M., Schulte F., Bongards M., Rehorek A. // Chem. Eng. Techol. 2016. V. 39. N 4. P. 627-636. DOI: $10.1002 /$ ceat.201500334 
[5] Basov S., Platkov M., Goldberg I., Dankner Y., Weinstein M., Goryachev A., Raichlin Y., Sprecher E., Katzir A. Fiber optic middle infrared evanescent wave spectroscopy for early detection of melanoma // Optical fibers and sensors for medical diagnostics and treatment applications XIX. San Francisco: SPIE, 2019. V. 10872. P. 108720Y. DOI: $10.1117 / 12.2513312$

[6] Kim R., Park C.H., Moon J.H. // J. Korean Phys. Soc. 2015. V. 66. N 10. P. 1495-1498. DOI: $10.3938 / \mathrm{jkps} 66.1495$

[7] Красников С.В. // Вісник НТУ „ХПІ“. 2016. № 26. С. 56-59. DOI: $10.20998 / 2078 ? 9130.2017 .39 .115763$ 